\title{
LODO DE ESGOTO E SISTEMA RADICULAR DA PUPUNHEIRA ${ }^{(1)}$
}

\author{
Fernando Vinicio Armas Vega ${ }^{(2)}$, Marilene Leão Alves Bovi ${ }^{(3)}$, \\ Gentil Godoy J únior ${ }^{(4)} \&$ Ronaldo Severiano Berton ${ }^{(5)}$
}

\begin{abstract}
RESUMO
Os efeitos do lodo de esgoto sobre o sistema radicular da pupunhei ra foram estudados em experimento em campo, em blocos casualizados, instalado em U batuba (SP), em julho 2001, na densidade de 5.000 plantas ha-1. As doses de lodo de esgoto fresco $\left(79,7 \%\right.$ de umidade) utilizadas foram de $0,38,76$ e $152 \mathrm{t} \mathrm{ha}^{-1}$, equivalentes a $0,100,200$ e $400 \mathrm{~kg} \mathrm{ha}^{-1} \mathrm{de} \mathrm{N}$. Os tratamentos foram aplicados no sulco de plantio, adicionando-se $15 \mathrm{~g}$ por planta de $\mathrm{KCl}$ como fonte de $\mathrm{K}$. A análise do sistema radicular foi efetuada doze meses após, por meio de trado e de trincheiras e com o auxílio de fotos digitais. Detectou-se que o sistema radicular de pupunheiras com um ano de campo estava concentrado nas camadas superficiais (acima de $75 \%$ nos primeiros $20 \mathrm{~cm}$ ), assim como em distâncias de até $0,5 \mathrm{~m}$ da base da planta. 0 lodo de esgoto modificou positivamente a densidade do solo, alterando também favoravelmente a densidade das raízes. Houve aumento na biomassa radicular proporcional às doses de lodo de esgoto, existindo uma relação direta daquela com a fitomassa aérea. Doses de lodo equivalentes a 200 e $400 \mathrm{~kg}$ de $\mathbf{N}$ contribuíram para aprofundar o sistema radicular e proporcionaram maior quantidade relativa de raízes finas.
\end{abstract}

Termos de indexação: Bactris gasi paes, biossólido, densidade radicular, palmito, raiz.

\footnotetext{
(1) Parte de Tese de Mestrado do primeiro autor, apresentada ao I nstituto Agronômico de Campinas - IAC. Recebi do para publicação em janeiro de 2004 e aprovado em dezembro de 2004.

(2) Pós-graduando do Instituto Agronômico de Campinas - IAC. Caixa Postal 28, CEP 13001-970 Campinas (SP). Bolsista Fundag. E-mail: fernandoarmas@yahoo.com.br

(3) Pesquisador do Centro de Horticultura, IAC. E-mail: mlabovi@ac.sp.gov.br

(4) Pesquisador da Unidade de Pesquisa e Desenvolvimento de U batuba, APTA. Rod. Oswaldo Cruz 5061, CEP 13680-000. Ubatuba (SP). E-mail: aptauba@pratica.com.br

(5) Pesquisador do Centro de Solos e Recursos Ambientais, IAC. E-mail: rsberton@iac.sp.gov.br
} 


\title{
SUMMARY: SEWAGE SLUDGE DOSES AND THE ROOT SYSTEM OF PEACH PALM
}

\begin{abstract}
The effects of sewage sludge doses on the root system of peach pal $m$ were studied in a field experiment, in randomized completebl ocks, carried out in U batuba, stateof São Paulo, Brazil. Thetrial was set up in J uly 2001, with a density of 5,000 plants ha-1. The sewage sludge doses ( $79.7 \%$ water content) were $0,38,76$, and $152 \mathrm{t} \mathrm{ha}^{-1}$, which wereequivalent to doses of $0,100,200$, and $400 \mathrm{~kg} \mathrm{ha}^{-1}$ of $\mathrm{N}$. The treatments were applied in the planting furrow, and every plant was provided with $\mathrm{K}$ by a dose of $15 \mathrm{~g}$ potassium chloride. Theroot system was analyzed oneyear after planting using soil auger and digging of trenches and with the help of digital images. It was concl uded that theroot system of oneyear old peach palm was concentrated in the upper soil layer (over $75 \%$ in the $0-20 \mathrm{~cm}$ surfacelayer), and within a horizontal distance of $0.50 \mathrm{~m}$ from the pal $\mathrm{m}$ trunk. The sewage sludge positivel $y$ modi fied thesoil density as well as theroot density. Therewas an increment in root biomass proportional to the sludge doses, and there was a positive linear relationship between the root and shoot biomass. Sludge doses equival ent to 200 and $400 \mathrm{~kg} \mathrm{ha}^{-1}$ of $\mathrm{N}$ all owed the root system to explore deeper soil layers, as well as the development of more fine roots compared to the other treatments.
\end{abstract}

Index terms: Bactris gasipaes, biosol id, heart-of-palm, pejibaye, root density.

\section{NTRODUÇÃO}

Ao descrever eestudar uma planta, énorma geral subdividi-la em duas partes de acordo com a posição acima e abaixo da superfície do solo, denominadas, respectivamente, parte aérea e parte radicular, permitindo esta última a extração de água e nutrientes, assim como a fixação dela no solo.

O sistema radicular da pupunheira (Bactris gasipaes Kunth) é semel hante ao apresentado por outras palmeiras, sendo do tipo fasciculado. Eletem origem na porção basal do bulbo, em uma região conhecida como "disco" ou "plateau radicular". Deste saem raízes grossas que se ramificam, num ângulo próximo a 90 , gerando outras mais finas (Vandermeer, 1977; Tomlinson, 1990).

A maior percentagem da massa radicular da pupunheira, 58 a $75 \%$, concentra-se nos primeiros $20 \mathrm{~cm}$ de profundidade do solo, dependendo do tipo deste. Segundo al guns autores (Vandermeer, 1977; Bassoi et al., 1999), grande parte do sistema radicular encontra-se até $40 \mathrm{~cm}$ de distância da touceira. De acordo com Ferreira et al. (1980), em sol os da Amazônia brasileira o sistema radicular da pupunheira pode chegar a uma distância de cerca de 1,50 $\mathrm{m}$ em raio e até $2,0 \mathrm{~m}$ de profundidade.

O sistema radicular das palmeiras, em geral, é composto por raízes primárias, secundárias, terciárias e quaternárias, todas elas desprovidas de pêl os absorventes (Tomlinson, 1990; J ourdan \& Rey, 1997). As terciárias e quaternárias são consi deradas como os órgãos principais de absorção e podem ser bastante afetadas pela estrutura do sol o, bem como pelos teores de umidade, oxigênio, elementos minerais e matéria orgânica do solo (Macêdo \& Rodrigues, 2000).

A matéria orgânica (MO), além das propriedades químicas, atua como condicionador do solo, modificando suas características físicas, notando-se mai or desenvolvimento do sistema radicular das plantas em sol os com presença de matéria orgânica, apresentando resposta positiva a doses crescentes desta (Libardi \& Lier, 1999; Yanez et al., 1999).

O lodo de esgoto é o material sólido $(0,01 \%)$ das águas residuais que, além de conter teores significativos de nutrientes, é utilizado basicamente como condicionador do sol o pel os al tos teores de MO (40-60\%) que apresenta (Tsutiya, 2001). Por sua vez, a dinâmica da MO em ecossistemas tropicais é muito importante, graças à rápi da decomposição do material, humificação e mineralização deste, ocasionando transformações químicas, físicas e biológicas no solo a curto e longo prazo (Silva \& Pasqual, 1999).

Pela grande dificuldade na análise do sistema radicular de plantas perenes, vários métodos diretos foram desenvolvidos, tais como: perfurações com trado, escavações, monolitos com placas de pregos, trincheiras com contagem manual, placas com parede de vidro e diferentes tipos de rhizotron, dentre outros (Guimarães et al., 1997; J orge, 1999; Medina \& N eves, 1999). N o entanto, com o avanço da informática, surgiram novos métodos para análise do sistema radicular, que usam câmeras de vídeo e análise de imagens com programas computacionais especializados, ideais para culturas perenes como no caso das palmeiras (J orge, 1999; Schroth et al., 1999). 
Guimarães et al. (1997) compararam os métodos que exigem abertura de trincheira, observando que aquele que utiliza digitalização de imagens tem a vantagem de apresentar melhor distribuição espacial das raízes no perfil. Por sua vez, conforme ressaltado por Medina \& Neves (1999), o método de contagem manual de raízes permite uma avaliação rápida da distribuição do sistema radicular em campo, possibilitando, ainda, observar a existência de al gum impedimento físico ao enraizamento.

Alguns autores consideram o método de imagens digitalizadas um dos mais eficientes, já que os resultados podem levar a maior exatidão do que os obtidos por contagem manual (J orge, 1999; Schroth et al., 1999). No entanto, há necessidade de mel hor preparo dos perfis, assim como de equipamento digitalizador especial (câmara digital ecomputador), o que faz com que esse método seja uma forma de avaliação mais custosa. Por outro lado, no método do trado, as informações obtidas são diferentes, com resultados expressos em densidade ( $\mathrm{g}$ de raiz por volume do solo). É um método de baixo custo e que permite efetuar grande número de amostragens no campo. Todavia, a variabilidade espacial do sistema radicular é um dos grandes problemas ao utilizar esse método, que propicia um coeficiente de variação muito el evado (Guimarães et al., 1997).

Estetrabal ho teve como objetivo avaliar, por meio de métodos complementares, o desenvol vimento do sistema radicular de pupunheiras, com doze meses de idade, em campo, considerando quatro doses de lodo de esgoto, aplicadas no sul co de plantio durante a instalação do experimento.

\section{MATERIAL E MÉTODOS}

Os efeitos do lodo de esgoto sobre o sistema radicular da pupunheira foram estudados em experimento em campo em U batuba (23०27' S, $45^{\circ} 04^{\prime}$ O, a seis metros de altitude). O clima da região é "Cfa", pela classificação de Köppen, tropical quente eúmido, com pluviosidade anual normal de $2.841 \mathrm{~mm}$, evapotranspiração potencial normal de $992 \mathrm{~mm}$, excedente normal de $1.849 \mathrm{~mm}$, temperatura média anual de $20,8{ }^{\circ} \mathrm{C}$ e déficit hídriconulo.

O sol oédassificado como Aluvial álico (Udifluvent), com boa drenagem. Trata-se de solo arenoso, com a seguinte composição granulométrica na profundidade de $0-15 \mathrm{~cm}$, em g kg${ }^{-1}$ : 100 de argila, 140 de silte, 130 de areia fina e 630 de areia grossa. Nas maiores profundidades, houve progressiva diminuição na percentagem de areia grossa e aumento da areia fina. A porosidade total na profundidade de $0-20 \mathrm{~cm}$ é de $49,97 \%$, sendo constituída por 29,65 \% de macroporos e 20,32\% de microporos (J orge \& Bovi, 1994). A densidadeglobal do solo está em torno de 1,00 a 1,05 g cm${ }^{-3}$ (Vega, 2003). Considerandoa acidez excessiva, foi realizada aplicação de cal cário dol omítico (28 \% de CaO, 16 \% de $\mathrm{MgO}$ e $76 \%$ de PRNT) em toda a área experimental antes da instalação do experimento. Quarenta e cinco dias após a calagem, o solo apresentou as seguintes características químicas médias: $\mathrm{pH}_{\mathrm{CaCl}_{2}} 5,4$; matéria orgânica $22,18 \mathrm{~g} \mathrm{dm}^{-3}$; $P_{\text {resina }} 7,94 \mathrm{mg} \mathrm{dm}^{-3} ; \mathrm{K} 1,60 \mathrm{mmol}_{\mathrm{c}} \mathrm{dm}^{-3} ; \mathrm{Ca}$ $19,85 \mathrm{mmol}_{\mathrm{c}} \mathrm{dm}^{-3} ; \mathrm{Mg} \mathrm{8,88} \mathrm{mmol}_{\mathrm{c}} \mathrm{dm}^{-3} ; \mathrm{H}+\mathrm{Al}$ $36,44 \mathrm{mmol}_{\mathrm{c}} \mathrm{dm}^{-3}$; CTC $66,92 \mathrm{mmol}_{\mathrm{c}} \mathrm{dm}^{-3} ; \mathrm{Fe}$ 27,15 mg dm${ }^{-3}$; Mn 1,46 $\mathrm{mg} \mathrm{dm}^{-3}$; Cu 0,25 mg dm${ }^{-3}$;

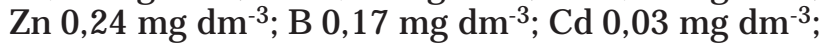

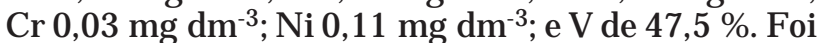
utilizada resina trocadora de íons para a extração de $\mathrm{K}, \mathrm{Ca}, \mathrm{Mg}, \mathrm{H}+\mathrm{Al}$ e CTC , seguindo métodos propostos por Raij \& Quaggio (2001). Por sua vez, $\mathrm{Fe}, \mathrm{Mn}, \mathrm{Cu}, \mathrm{Zn}, \mathrm{B}, \mathrm{Cd}, \mathrm{Cr}$ e Ni foram extraídos com DTPA em pH 7,3 (Abreu et al., 2001).

O experimento foi instalado em julho de 2001, utilizando-se mudas de pupunheira do ecotipo Putumayo, com 10 meses de idade. Foi delineado em esquema deblocos casual izados, com seis blocos equatro tratamentos, tendo 36 plantas por parcela (6 linhas x 6 plantas por linha), das quais apenas as 16 plantas internas foram mensuradas periodicamente, visando reduzir o efeito de borda. Foi utilizada a densidade de 5.000 plantas ha-1 $^{-1}$ no espaçamento de $2 \times 1 \mathrm{~m}$.

As doses de lodo de esgoto aplicadas foram calculadas levando em consi deração as recomendações para o cultivo (Bovi \& Cantarella, 1996), a composição química média do lodo da Estação de Tratamento de Esgoto de Bertioga, os teores de N prontamente disponível e o procedimento adotado por Tsutiya (2001), resultando em 0, 38, 76 e 152 t ha-1 $^{-1}$ de lodo de esgoto fresco ( $79,7 \%$ de umidade), equivalentes a 0, 100, 200 e $400 \mathrm{~kg} \mathrm{ha}^{-1}$. Os tratamentos foram aplicados, de uma única vez, no sulco de plantio, adicionando-se $15 \mathrm{~g}$ por planta de $\mathrm{KCl}$ como fonte de $K$. Maiores detalhes sobre a instalação e a condução do experimento são apresentados por Vega (2003).

Doze meses após o plantio, a densidade radicular, na camada de $0-20 \mathrm{~cm}$ de profundidade, foi avaliada pel o método do trado (Böhm, 1979). Foram retiradas três amostras na linha de plantio etrês na entrelinha, a $30 \mathrm{~cm}$ de distância da base da planta, para todos os tratamentos e blocos. A mesma amostragem foi utilizada para determinar a densidade do solo. As amostras foram individual menteacondicionadas em sacos plásticos el evadas aolaboratório onde as raízes foram separadas do solo, utilizando pinças de laboratório e, posteriormente, lavadas. As raízes, acondicionadas em sacos de papel, foram secas em estufa a $65^{\circ} \mathrm{C}$ até peso constante. Após secagem, foram caracterizadas em grossas ou R1, com diâmetros mai ores que 4,0 mm; médias ou R2, entre 2,0 a 4,0 mm; eraízes finas (R3 eR4) com diâmetros para R3 entre 1,0 e 1,9 mm, e R4, compreendendo raízes com diâmetro abaixo de $1,0 \mathrm{~mm}$. As médias dos dados foram analisadas graficamente, com o auxílio do programa Surfer 3.2 e expressas em percentagem de classes de raízes. 
Na mesma época (12 meses após o plantio), foi avaliada a distribuição do sistema radicular no perfil do solo pelo método de trincheiras (Böhm, 1979). Para tanto foram abertas duas trincheiras por tratamento. Tomou-se o cuidado de alocá-las em parcelas com plantas representativas da população de cada tratamento. Cada trincheira teve as dimensões de $2 \mathrm{~m}$ de comprimento, $1 \mathrm{~m}$ de largura e $1 \mathrm{~m}$ de profundidade. A distância da parede do perfil foi mantida a 0,3 $\mathrm{m}$ da base da planta. A distribuição do sistema radicular ao longo do perfil foi analisada com o auxílio de uma malha metálica de $1 \times 1 \mathrm{~m}$, com $20 \mathrm{~cm}$ de quadrícula e um total de $400 \mathrm{~cm}^{2}$ de superfície por quadrícula (Figura 1), segundo procedimento descrito por J orge (1999). Pela proximidade das plantas na linha, optou-se por considerar apenas a distância de $50 \mathrm{~cm}$ de cada lado da planta matriz, mantendo $1 \mathrm{~m}$ de profundidade. As imagens de cada quadrícula foram obtidas com câmera digital (Sony Mavica), sendo posteriormente editadas com o programa Microsoft Photo Editor, para regular o tamanho das fotos, assim como a escala de cores (256). O processamento e a análise das imagens foram feitos com o auxílio do programa SI ARCS 3.0 (Sistema Integrado para Análises de Raízes e Cobertura do solo), desenvolvido pela Embrapa. Os resultados obtidos foram interpretados graficamente por meio do programa Surfer 3.2. Dessa forma, foi possível visualizar a variabilidade espacial da resposta do sistema radicular às doses crescentes de lodo de esgoto no desenvolvimento e na distribui ção das raízes no perfil do solo, com base na média das parcelas.

Como há uma relação direta entre o crescimento do sistema radicular eo da parte aérea, procurou-se também caracterizar adequadamente esta última, deforma a propiciar inferências relacionadas com a distribuição relativa entre fitomassa aérea e radicular. Para tanto, as plantas das parcelas onde foram abertas as trincheiras foram medidas, anotando-se altura da haste principal (medida do solo até à inserção da folha mais nova), perímetro da haste principal (medido na base ou coleto), número de perfilhos da touceira e estimativa da fitomassa aérea da haste principal (massa fresca). Esta última foi estimada por meio de equação alométrica do tipo $y=a x^{(b)}$, com $a=2,7289$ e $b=2,0456$, como constantes da equação, ex $=$ altura da planta atéà inserção da fol ha +1 (a primeira fol ha mais jovem, completamente expandida), como variável, segundo Vega (2003).

Todos os dados foram submetidos à análise de regressão, seguida de ajuste de função pol inomial, em virtude da natureza quantitativa dos tratamentos (doses de lodo de esgoto), tomando como base a equivalência em quilos de $\mathrm{N}$ prontamente disponível por hectare. Essas doses (0 a $400 \mathrm{~kg} \mathrm{ha}^{-1}$ de $\mathrm{N}$ ) são equivalentes às quantidades de lodo de esgoto utilizadas durante o plantio e possibilitam comparação com resultados obtidos quando do uso de outra fonte do nutriente (Tsutiya, 2001). A escol ha da equação de melhor ajuste foi baseada na significância do efeito da regressão, dos desvios da regressão testados pelo teste $\mathrm{F}$ a $5 \%$ e no maior coeficiente de determinação $\left(R^{2}\right)$. Os coeficientes das equações de regressão foram testados até 10 \% pel o teste " $t$ ". Quando da comparação dos resultados obtidos na linha e entrelinha, foi utilizada análise de variância, com comparação entre médias feita pelo teste $\mathrm{F}$ a $5 \%$.

\section{RESULTADOS E DISCUSSÃO}

A análise de regressão aplicada aos dados de densidade de raízes da pupunheira na camada de

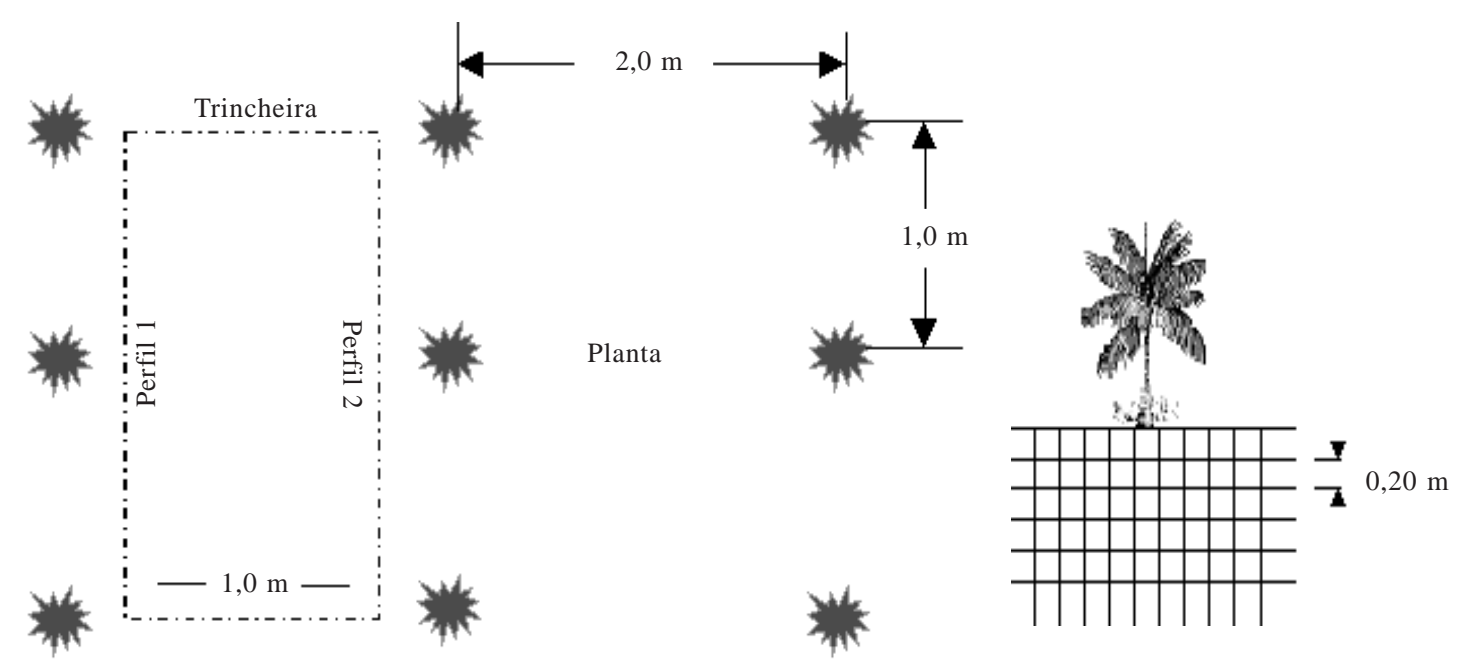

Figura 1. Localização das trincheiras e malha, indicando no perfil as posições de coleta de imagens do sistema radicular das pupunheiras, 12 meses após aplicação de lodo de esgoto e plantio. 
0-20 cm de profundidade, obtidos pelo método do trado, mostrou significância para os efeitos linear $\left(P=0,05, R^{2}=0,91\right)$ e quadrático $\left(P=0,03, R^{2}=\right.$ $0,99)$, quando as amostras foram retiradas na linha de plantio. Por sua vez, para a amostragem na entrelinha, os efeitos não foram significativos (linear - $P=0,58, R^{2}=0,44$; quadrático - $P=0,32$ e $R^{2}=$ 0,46 ). A ausência de significância entre as doses na entrelinha era esperada, uma vez que o lodo foi aplicado apenas nas linhas de plantio e o espaçamento entre elas era de $2 \mathrm{~m}$.

A densidade radicular na linha de plantio, com base em matéria seca, aumentou significativamente de acordo com as doses crescentes de lodo de esgoto, chegando à densidade máxima de $3,22 \mathrm{~g} \mathrm{dm}^{-3}$, na dose 400 (F igura 2). Foram detectadas, portanto, de três a quatro vezes mais raízes na dose máxima de lodo de esgoto, quando comparada com as doses de 0,100 e 200. A equação que melhor expressou essa relação entrea densidade de raízes eas doses de $\mathrm{N}$, na camada de $0-20 \mathrm{~cm}$, foi: $\hat{\mathrm{y}}=0,79909-0,00054 \mathrm{x}$ $+0,00002 x^{2}$, com $R^{2}=0,99$, sendo $x$ as doses de $N$.

A densidade radicular obtida na dose 400 (3,22 $\mathrm{g} \mathrm{dm}^{-3}$, base seca) foi superior à encontrada por Ferreira et al . (1980) em pupunheiras adultas (al tura média de 9,14 m), em Latossolo Amarelo textura média. Esses autores obtiveram densidades radiculares em torno de 2,94 $\mathrm{g} \mathrm{dm}^{-3}$ (massa deraízes secas) a $50 \mathrm{~cm}$ de distância da base da planta. J á Bovi et al. (1999), em experimento com pupunheiras do ecotipo "microcarpa" Pará (com dois anos de plantio e com $70 \%$ das plantas aptas à colheita de palmito), onde foram testadas doses de $\mathrm{N}, \mathrm{P}$ e K, encontraram uma relação entre a densidade radicular e as doses de $\mathrm{N}$, com maiores densidades na dose $400 \mathrm{~kg} \mathrm{ha}^{-1}$ de $\mathrm{N}$, chegando a val ores de 3,90 a $6,35 \mathrm{~g} \mathrm{dm}^{-3}$ na linha de plantio, resultados, portanto, superiores aos encontrados no presente trabal ho. Esses autores reportaram ainda variação em torno de $38,6 \%$ na densidade radicular entreas progênies utilizadas, evidenciando que o material genético em uso tem influência marcante também no sistema radicular e não só na fitomassa aérea.

Ao comparar a linha e a entrelinha da dose de maior resposta (400 de N), observou-se um acúmulo do sistema radicular na linha de plantio, onde foi aplicado o lodo de esgoto, sendo acima de duas vezes superior à quantidade de raízes encontradas na entrelinha (Figura 2). Essa variação poderia ser resultante de possível diferença na densidade do solo, assim como da quantidade de nutrientes na linha (Vega, 2003), o que gera uma maior proliferação do sistema radicular, já que a pupunheira, mesmo sendo planta rústica e adaptada a sol os com baixos teores de nutrientes, tem melhor desenvolvimento radicular quando os fatores edáficos são adequados (Villachica, 1996). Defato, os resultados da análise da densidade do solo possi bilitam uma comparação interessante. Nota-se (F igura 2), a relação inversa

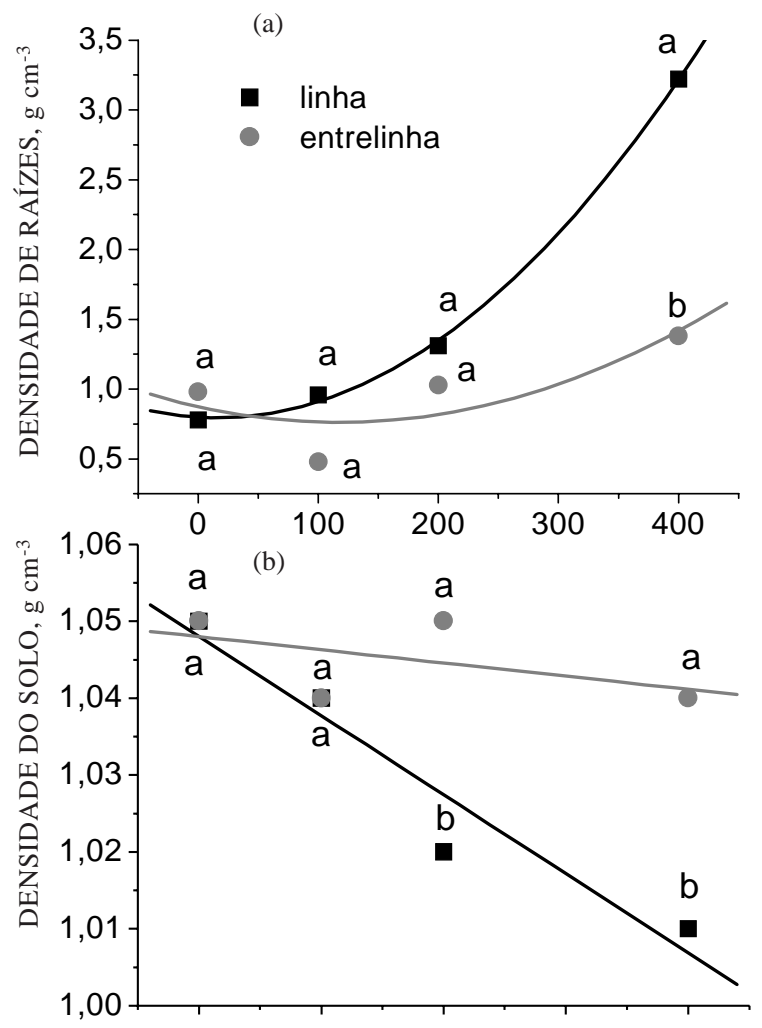

DOSE DE N, kg ha ${ }^{-1}$

Figura 2. Densidade de raízes (DR) de pupunheira (a) e densidade do solo (DS) (b), na camada de $0-20 \mathrm{~cm}$ de profundidade, considerando as doses de $\mathbf{N}$ (equivalentes às quantidades de lodo de esgoto utilizadas), obtidas doze meses após o plantio. Letras iguais na mesma dose representam que linha e entrelinha não diferiram entre si pelo teste $F$ a $5 \%$. (DR linha $=$ $0,799-0,0005 x+0,00002 x^{2}, \operatorname{com} R^{2}=0,99 ; S_{\text {linha }}$ $=1,048-0,0001 x$, com $\left.R^{2}=0,92\right)$.

entre densidade de raízes (a) e densidade do solo (b), especialmente na linha de plantio $\left(r=-0,85^{*}\right)$. A menor densidade do solo $\left(1,01 \mathrm{~g} \mathrm{~cm}^{-3}\right)$ foi obtida, na linha, na dose 400 de $\mathrm{N}$, e a maior densidade na dose $0\left(1,05 \mathrm{~g} \mathrm{~cm}^{-3}\right)$ nos dois locais de amostragem. A equação que mel hor expressa essa relação entrea densidade do sol o eas doses de N, na linha de plantio e considerando apenas a camada de 0 - $20 \mathrm{~cm}$, é: $\hat{y}$ $=1,048-0,00001 x$, com $R^{2}=0,93$ e sendo $x$ as doses de $N$. A análise de regressão não indicou efeitos significativos para a entrelinha $\left(P=0,49 ; R^{2}=-0,51\right)$. Novamente, pode-se dizer que a ausência de significância entre as doses na entrelinha era esperada, visto que o lodo foi aplicado apenas nas linhas de plantio e o espaçamento entre elas era de $2 \mathrm{~m}$.

Dada a relação existente entre a densidade do solo e algumas de suas características físicas, é 
possível que a adição de lodo de esgoto no sulco de plantio (linha), especialmentenas maiores doses (200 e 400), com diferenças significativas quando comparadas com a entrelinha, tenha contribuído também para mel horar a porosidade ea capacidade de retenção de água no solo, conforme relato de Yanez et al. (1999). Estudando os efeitos do uso da matéria orgânica (MO) na recuperação de áreas degradadas em zonas subtropicais, esses autores (Yanez et al., 1999) ressaltaram as mudanças nas características físicas do solo advindas da sua utilização. Eles encontraram correlações significativas entre os teores de MO e densidade, permeabilidade, por osi dadetotal er etenção deágua no solo. Alterações da ordem de $68 \%$ foram detectadas, por esses autores, para a densidade do solo. Esta foi inversamente proporcional ao teor de MO do solo, que variou de 0,68 a 3,15\%.

A análise de regressão para percentagem relativa de raízes, na camada de $0-20 \mathrm{~cm}$, considerando as doses de lodo, não foi significativa $\left(R^{2}<0,50\right.$; $P>0,05)$, tanto na linha quanto na entrelinha. Não obstante, independentemente das doses de lodo de esgoto aplicadas, foram observadas quantidades el evadas de raízes, especial mente as das classes R 1 (30\%), responsáveis pela sustentação, e as das classes R3/R 4 (25 \%), atuantes na absor ção de água e nutrientes, na linha de plantio, quando comparadas às da entrelinha (Figura 3). As diferenças na percentagem total de raízes entre os dois locais de amostragem foram estatisticamente significativas pelo teste $\mathrm{F}$ a $5 \%$, e ocorreram, possivelmente, em razão da maior compactação do solo na entrelinha, causada pelas freqüentes roçadas, necessárias para diminuir a competição com ervas daninhas, com reflexos diretos na densidade do solo, bem como no menor teor de nutrientes existentes na entrelinha (Vega, 2003).

$\mathrm{Na}$ comparação da distribuição espacial do sistema radicular para os diferentes tratamentos (Figura 4) e obtida com a digitalização de imagens no perfil da trincheira $\left(\mathrm{cm}^{2}\right.$ de raiz por $400 \mathrm{~cm}^{2}$ de solo), nota-se, de forma geral, que a pupunheira, 12 meses após o plantio, acumulou a maior quantidade do sistema radicular na camada de 0$20 \mathrm{~cm}$ de profundidade. Para a distribuiçãolateral, não houve um padrão definido, em razão, provavelmente, da proximidade das plantas na linha (espaçadas de $1 \mathrm{~m}$ ) e da sobreposição dos sistemas radiculares nessa dimensão. Apenas na dose 400, observou-se maior concentração de raízes na parte central da área estudada, localizada logo abaixo do estipe da palmeira. J á em profundidade, cabe destacar que, para as doses 400 e 200, foram encontradas raízes até $40 \mathrm{~cm}$, enquanto para as doses 0 e 100, somente na camada superficial.

Observou-se um incremento da superfície radicular, especialmente nas doses maiores de lodo de esgoto (200 e 400) (Figura 4). A dose 400
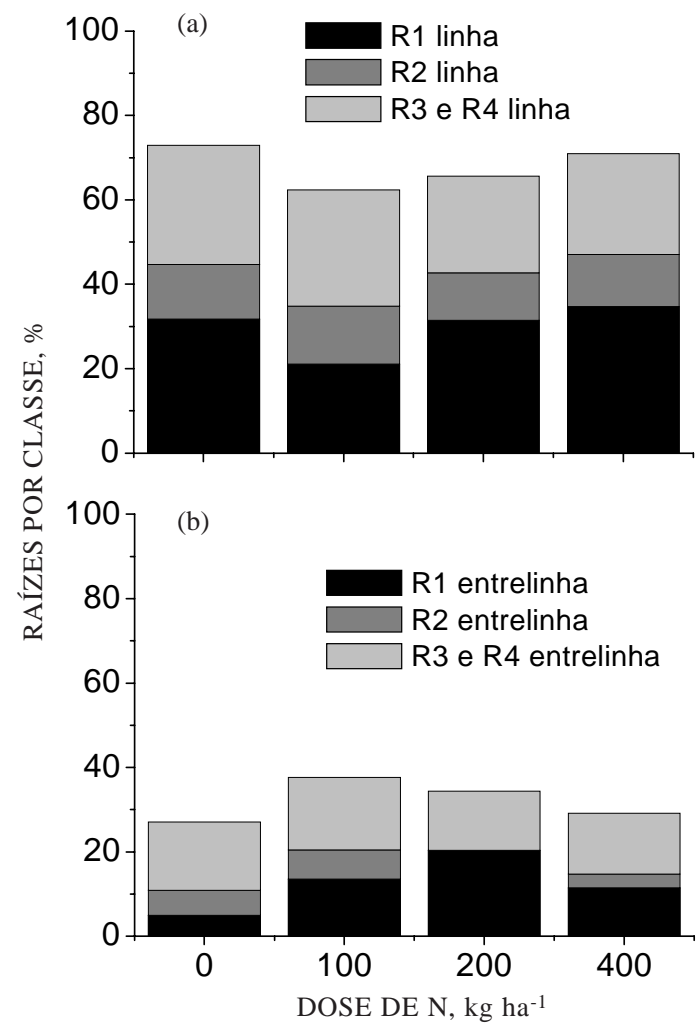

Figura 3. Comparação percentual entre classes de raízes ( $R 1$, $R 2$ e $R 3 / R 4$ ) de pupunheiras com um ano de idade, encontradas na linha (a) e entrelinha (b), considerando as doses de $\mathbf{N}$ (equivalentes às quantidades de lodo de esgoto utilizadas).

apresentou maior concentração de raízes na camada de $0-20 \mathrm{~cm}$ (onde foi aplicado o lodo de esgoto), variando de 2,0 a $12,9 \mathrm{~cm}^{2}$ de raiz por $400 \mathrm{~cm}^{2}$ de solo. Valores menores que $2,0 \mathrm{~cm}^{2}$ de raiz por $400 \mathrm{~cm}^{2}$ de solo foram encontrados nas camadas subseqüentes.

Distribuição similar do sistema radicular foi reportada anteriormente por al guns autores, tanto em pupunheira (Ferreira et al., 1980; Villachica, 1996; Bovi et al., 1999; Ramos, 2002), quanto em outras palmeiras (Passos, 1997; Da Conceição \& Müller, 2000), para as quais, independentemente do manejo físico, químico ou biológico do solo, a maior percentagem do sistema radi cular encontrava-se nas camadas superficiais do perfil do solo, entre 0-20 cm, sendo um pouco menor na faixa de $20-40 \mathrm{~cm}$ de profundidade. Para a maior parte das palmeiras estudadas, 50 a $80 \%$ do sistema radicular concentrase nessas duas camadas.

Comparando o desenvolvimento do sistema radicular nas diferentes doses de lodo de esgoto, observou-se que o desenvol vimento, tanto na lateral quanto na vertical, foi maior quanto maior a dose equivalente de N. Resultados semel hantes foram obtidos por Ramos (2002) em pupunheiras com 


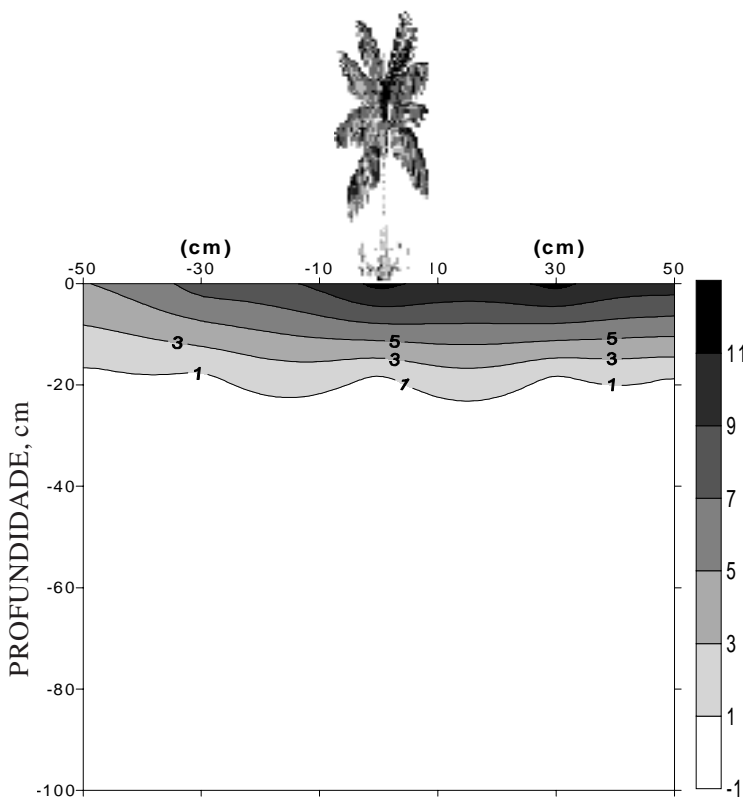

DOSE $0, \mathrm{~kg} \mathrm{ha}^{-1}$ de N
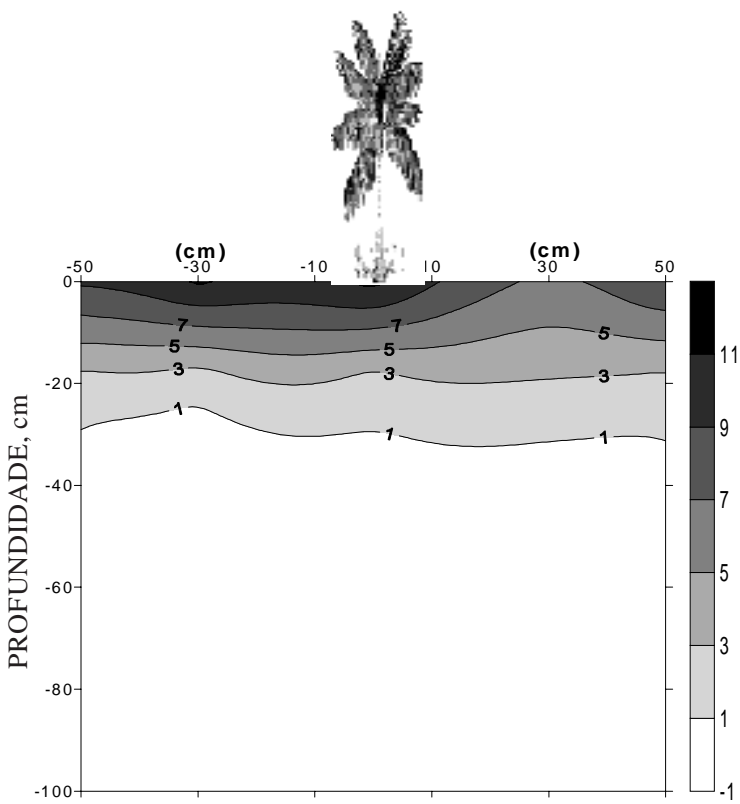

DOSE 200, $\mathrm{kg} \mathrm{ha}^{-1}$ de N

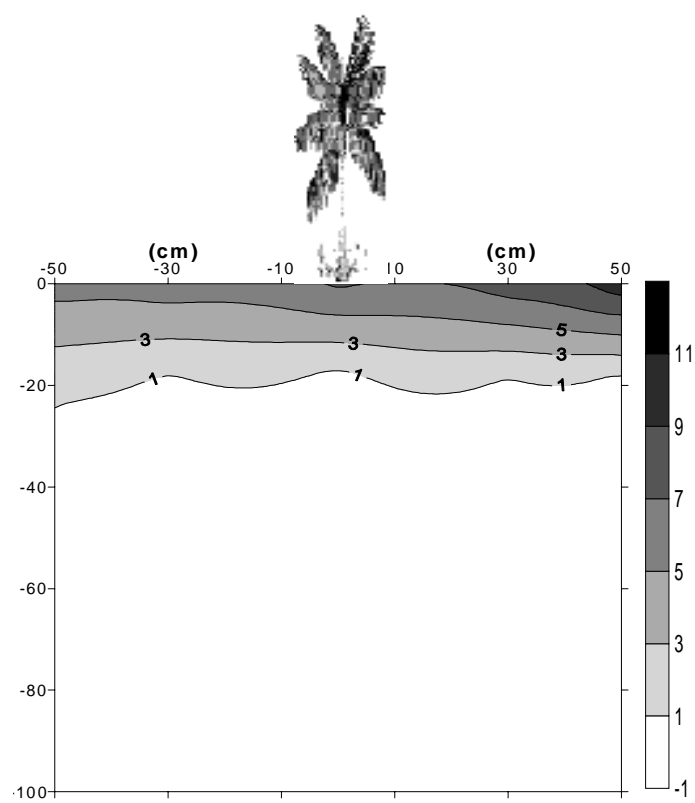

DOSE $100, \mathrm{~kg} \mathrm{ha}^{-1}$ de N

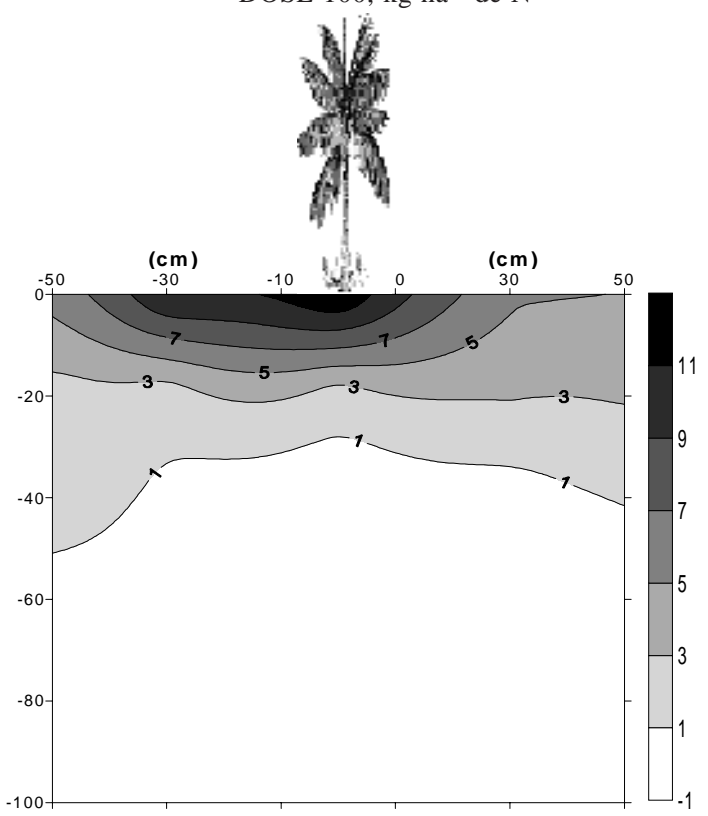

DOSE 400, $\mathrm{kg} \mathrm{ha}^{-1}$ de N

Figura 4. Distribuição espacial da área de raízes $\left(\mathrm{cm}^{2}\right.$ de raiz por $400 \mathrm{~cm}^{2}$ de solo) da pupunheira, considerando as doses de lodo de esgoto, doze meses após o plantio. Na vertical estão as escalas das i solinhas para efeito de comparação entre as doses. As isolinhas compreenderam o intervalo de -1 a $13 \mathrm{~cm}^{2}$ de raiz por $400 \mathrm{~cm}^{2}$ de solo.

20 meses de plantio e altura média de 1,50 m, cultivadas em solo argiloso no planalto paulista e adubadas com fertilizante químico. A autora observou que, no tratamento com melhores resultados (400 kg ha-1 de $\mathrm{N})$, o sistema radicular chegou a profundidades abaixo de $0,6 \mathrm{~m}$; com val ores de 17, 10, 3 e $1 \mathrm{~cm}^{2} 400 \mathrm{~cm}^{-2}$, para as camadas de $0,0-0,2,0,2-0,4,0,4-0,6$ e 0,6-0,8 $\mathrm{m}$ de profundidade, respectivamente. É provável que a diferença de idade, a maior fertilidade natural do sol o e o efeito da irrigação no experimento de Ramos (2002) sejam responsáveis pela maior superfície e profundidade de raízes observadas pela autora, quando comparadas aos resultados do presente estudo.

Embora a distribuição espacial seja importante para dar uma idéia do al cance do sistema radicular, ela não contempla o diâmetro das raízes. Conforme detal hado por Toml inson (1990), o sistema radicular das palmeiras é composto por raízes primárias, 
secundárias, terciárias equaternárias, denominadas assim deacor do com sua ontogenia eseus diâmetros. Enquanto as raízes primárias, mais grossas, são responsáveis pelo ancoramento das plantas, as terciárias e quaternárias são consideradas como os órgãos principais de absorção. Por possuírem diâmetros e comprimentos pequenos, elas podem ser bastante afetadas pela estrutura do solo, bem como pelos teores de umidade, oxigênio, elementos minerais e MO (J ourdan \& Rey, 1997; Macêdo \& Rodrigues, 2000). Dessa forma, a determinação da proporção rel ativa de raízes grossas efinas aolongo do perfil é fundamental em estudos de sistema radicular que envolve doses de al gum tipo de MO.

Corroborando o que foi dito anteriormente, observou-se que a maior percentagem das raízes da pupunheira, doze meses após o plantio, está basicamente na camada de 0-20 cm, com 75 a $95 \%$ do total deraízes presentes nessa camada (Figura 5). $\mathrm{Na}$ camada imediatamente abaixo $(20-40 \mathrm{~cm})$, foram encontradas de 5 a $20 \%$, enquanto se detectou de 0 a $5 \%$ do total de raízes na camada de $40-60 \mathrm{~cm}$. Houve melhor distribuição das raízes em profundidade para as doses 200 e $400 \mathrm{~kg} \mathrm{ha}^{-1}$ de N, em que cerca de $5 \%$ do total de raízes nestes tratamentos foi encontrado na camada de $40-60 \mathrm{~cm}$.

Observou-se que, do total de raízes, $10 \%$ corresponderam a raízes grossas (diâmetros acima de $2 \mathrm{~mm}$ e correspondentes às classes R 1 e R2), consideradas como de sustentação, independentemente das camadas e das doses anal isadas. Por outro lado, as raízes finas (diâmetros abaixo de $2 \mathrm{~mm}$ e correspondentes às classes R3 e R4) representaram cerca de 70 a $80 \%$ do total de raízes na camada de 0-20 cm. Na camada subseqüente $(20-40 \mathrm{~cm})$, elas constituem $25 \%$ do total, passando a valores menores que $8 \%$ na camada de $40-60 \mathrm{~cm}$. Tal como aconteceu com as raízes grossas, o presente estudo mostrou queas raízes terciárias (R3) equaternárias (R4), que são as encar regadas da absorção deágua e nutrientes, encontram-seem altas quantidades, com melhor desenvolvimento e melhor distribuição em profundidade, nas condições de doses mai ores de lodo de esgoto. Tal fato se deve, provavelmente, à melhor disponibilidade de água e nutrientes nessas dosagens, além de menor densidade do solo, o que resultou em maior crescimento radicular. Resultados de vários autores, dentre eles Libardi \& Lier (1999), Silva \& Pasqual (1999) e Yanez et al. (1999), corroboram essa inferência, dado o efeito benéfico da MO na melhoria de algumas propriedades do solo, tais como: densidade, porosidade e capacidade de retenção de água.

A análise dos resultados, tanto deárea superficial quanto da distribuição relativa das raízes ao longo do perfil, permite constatar que, nas condições do presente experimento, o sistema radicular da pupunheira émuito superficial ( 75 a $95 \%$ das raízes concentram-se nos primeiros $20 \mathrm{~cm}$ desolo), até mais do que o reportado anteriormente por alguns autores
(Vandermeer, 1977; Villachica, 1996; Bassoi et al., 1999; Ramos, 2002). As diferenças nas características físicas e químicas dos solos, do material genético e da idade das plantas dos estudos citados, podem ser apontadas como os principais fatores responsáveis pela ligeira discrepância dos resultados.

Discutiu-se, até então, que o sistema radicular da pupunheira, avaliado aos dozemeses deidade, mostra respostas positivas ealtamente correl acionadas com as doses de lodo de esgoto aplicadas no sulco ainda

TOTAL DE RAÍZES, \%

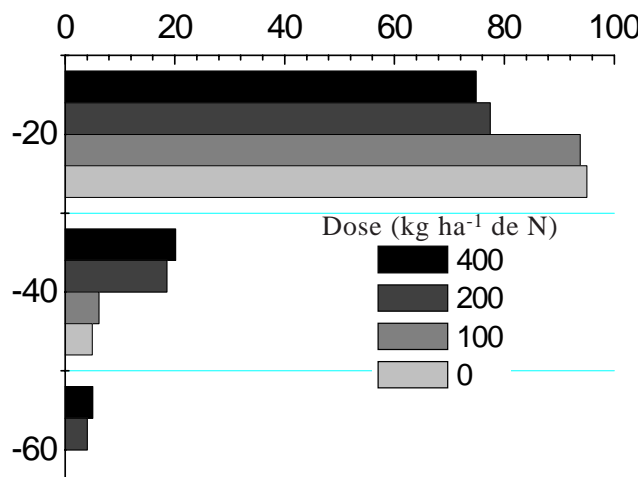

RAÍZES GROSSAS, \%

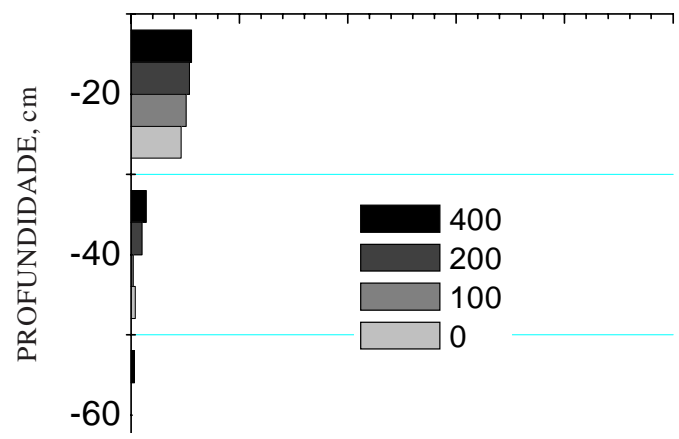

RAÍZES FINAS, \%

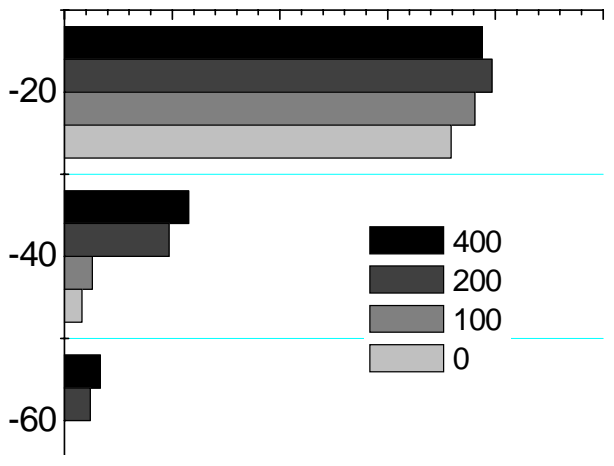

Figura 5. Percentagem de raízes totais, grossas e finas, de pupunheiras, doze meses após o plantio, nas camadas do perfil da trincheira, caracterizadas em grossas ou R1 e R2, com diâmetros maiores que 4,0 mm e entre 2,0 a 4,0 mm; e raízes finas ( $R 3$ e $R 4$ ) com diâmetros para $R 3$ entre 1,0 e 1,9 mm, e R4, compreendendo raízes com diâmetro abaixo de 1,0 mm. 
durante o plantio. Respostas semelhantes foram obtidas para variáveis relacionadas com a parte aérea, tais como: perímetro e altura da haste principal, número médio de perfilhos e fitomassa aérea, avaliadas na mesma data. Para essas quatro variáveis, foi constatado efeito linear significativo e positivo $\left(R^{2}=0,97,0,91,0,91\right.$ e 0,$93 ; P=0,01,0,05$, 0,04 e 0,03 , respectivamente), conforme as doses crescentes de N. Observa-se que as plantas que receberam as maiores doses de lodo de esgoto durante o plantio (correspondentes a 200 e $400 \mathrm{~kg} \mathrm{ha}^{-1}$ de N) apresentaram, doze meses após a aplicação, perímetros da haste principal variando de 0,32 a 0,37 m e alturas que variaram de 1,19 a $1,50 \mathrm{~m}$, respectivamente, quase duas vezes superior à dose 0 (Figura 6). Nesses mesmos tratamentos houve um acúmulo da fitomassa aérea, com base em massa fresca, em torno de 3,90 e 6,25 kg planta-1, e maior perfilhamento (médias de 5 e 7 perfilhos por touceira, respectivamente), evidenciando que maior desenvolvimento radicular esteve sempre associado ao mai or crescimento da parte aérea. Tal fato evidencia que o aumento do sistema radicular
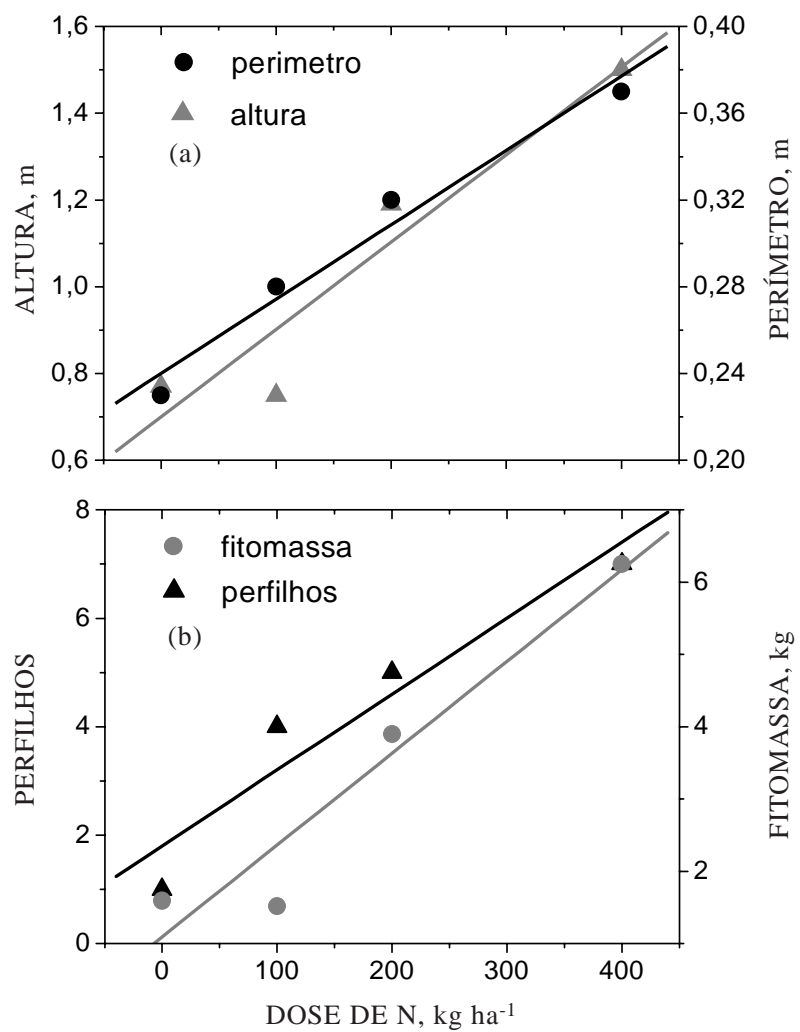

Figura 6. Desenvolvimento da parte aérea avaliado pela altura ( $\left.\hat{y}=0,7+0,002 x ; R^{2}=0,91\right)$ e perímetro $\left(\hat{y}=0,24+0,0003 x ; R^{2}=0,97\right)$ da haste principal (a), bem como pelo número de perfilhos ( $\hat{y}=1,8+0,014 x ; R^{2}=0,91$ ) efitomassa $\left(\hat{y}=1,09+0,013 x ; R^{2}=0,93\right)$ aérea (b) de pupunheiras com 12 meses de idade considerando as doses de $\mathbf{N}$ (equivalentes às quantidades de lodo de esgoto utilizadas). relaciona-se com o crescimento da parte aérea da planta e, mais ainda, com as condições químicas e físicas do solo, sendo estas últimas os fatores determinantes do desenvolvimento do sistema radicular e da fitomassa aérea.

Tanto para as variáveis área superficial e percentagem relativa de raízes, quanto para as referentes ao crescimento da parte aérea, não foram detectados efeitos quadráticos significativos, apenas lineares e positivos, indicando que mesmo a dose de lodo de esgoto mais al ta empregada (152 t ha-1 e correspondente a $400 \mathrm{~kg} \mathrm{ha}^{-1}$ de $\mathrm{N}$ prontamente disponível) não apresentou toxidez às pupunheiras. Com base apenas na resposta da planta poder-se-ia inferir que doses maiores de lodo poderiam ser utilizadas. No entanto, deve-se atentar para a perda de $\mathrm{N}$ por lixiviação e escorrimento superficial, quando do uso de lodo de esgoto, mesmo quando aplicado no sulco. Conforme relatado por Oliveira (1995), as chances de contaminar as águas subsuperficiais com nitrato, proveniente da lixiviação do N mineral do lodo de esgoto, são grandes. Por isso, as dosagens a serem aplicadas nas diversas culturas devem ser pautadas nas necessi dades de $\mathrm{N}$ das plantas, obedecendo a normas rígidas de aplicação e indicação de parcelamento. Procura-se, dessa forma, evitar a geração de nitrato em quantidades excessivas que venha a lixiviar no perfil do solo, colocando em risco a qualidade das águas subsuperficiais.

\section{CONCLUSÕES}

1. O sistema radicular de pupunheiras com um ano de idade concentrou-se, em sua mai oria, na camada superficial do solo (0-20 cm profundidade), assim como em distâncias de até $0,5 \mathrm{~m}$ da base da planta.

2. Percebeu-se aumento da biomassa radicular, quando aumentada a dose de lodo de esgoto, existindo uma relação direta daquela com o crescimento da parte aérea da planta.

3. Doses el evadas de lodo de esgoto contribuíram para aprofundar o sistema radicular da pupunheira, proporcionaram maiores quantidades de raízes absorventes em relação às raízes totais e reduziram a densidade do solo.

\section{AGRADECIMENTOS}

Os autores agradecem à SABESP, pel o financiamento parcial do projeto de pesquisa, e à $\mathrm{FundAg}$, pela concessão de bolsa duranteo período final demestrado do primeiro autor. Agradecem ainda a Matheus deAguiar Rodrigues Cembranelli, peloapoiologístico, e à I sabella Clerici De Maria, do IAC eLúcio André de Castro J orge, da Embrapa Instrumentação Agropecuária, pela orientação nas análises. 


\section{LITE RATURA CITADA}

ABREU, C.A.; ABREU, M.F. \& ALMEIDA, J .C. Determinação de cobre, ferro, manganês, zinco, cádmio, cromo e chumbo em solos usando a solução de DTPA em pH 7,3. In: RAIJ , B. van; ANDRADE , J .C.; CANTARELLA, H. \& QUAGGIO, J .A., eds. Análise química para avaliação da fertilidade de sol os tropicias. Campinas, I nstituto Agronômico, 2001. 285p.

BASSOI, L.H.; FLORI, J .E.; ALENCAR, C.M.; SILVA, J .A.M. \& RAMOS, C.M.C. Distribuição espacial do sistema radicular da pupunheira em solos irrigados no Vale do São F rancisco. Eng. Agric., 19:163-176, 1999.

BOVI, M.L.A. \& CANTARELLA, H. Pupunha para extração de palmito. In: RAIJ , B. van; CANTARELLA, H.; QUAGGIO, J .A. \& FURLANI , A.M.C., eds. Recomendações de adubação para algumas culturas do estado de São Paulo. Campinas, Instituto Agronômico de Campinas, 1996. p.240-242. (Boletim Técnico, 100)

BOVI, M.L.A.; SPIERING, S.H. \& BARBOSA, A.M.M. Densidaderadicular de progênies de pupunheira em função de adubação NPK. Hortic. Bras., 17:186-193, 1999.

BÖHM, W. Methods of studying root system. Berlin, SpringerVerlag, 1979. 527p.

DA CONCEIÇÃO, H.E.O. \& MÜLLER, A.A. Botânica e morfologia do dendezeiro. In: VIÉGAS, I.J .M.; MÜLLER, A.A., eds. A cultura do dendezeiro na amazônia brasileira. Belém, Embrapa - Amazônia Oriental/Manaus, Amazônia Ocidental, 2000. p.31-47.

FERREIRA， S.A.; CLEMENT， C.R. \& RANZANI， G. Contribuição para o conhecimento do sistema radicular da pupunheira (Bactris gasipaes H.B.K. - Guilielma gasipaes (H.B.K.) Bailey). Act. Amaz., 10:245-249, 1980.

GUIMARÃES, M.F.; ORGE, L.C.A.; DE MARIA, I.C.; TAVARES Fo, J .; BICUDO, S.J . \& CRESTANA, S. Três metodologias de avaliação de raízes: descrição, limitações e vantagens. In: SIMPÓSIO NACIONAL DE INSTRUMENTAÇÃO AGROPECUÁRIA, SIAGRO, 1., São Carlos, 1996. Anais. São Carlos, Embrapa CNPDIA, 1997. p.295-304.

J ORGE, L.A.C. Descrição detalhada do método de trincheira com produção de imagens para uso do SIARCS. In: WORKSHOP SOBRE DESENVOLVIMENTO DO SISTEMA RADICULAR: METODOLOGIAS E ESTUDO DE CASOS, 1., Aracaju, 1999. Anais. Aracaju, Embrapa Tabuleiros Costeiros, 1999. p.255-268.

J ORGE, J .A. \& BOVI, M.L.A. Influência das propriedades físicas e químicas do solo no crescimento da palmeira pupunha. In: CONGRESSO BRASILEIRO DE FRUTICULTURA, 13., Salvador, 1994. Resumos expandidos. Salvador, SBF , 1994. p.1145-1146.

J OURDAN, C. \& REY, H. Architecture and development of the oil-palm (Elaeis guineensis) acq.). Plant Soil, 189:33-48, 1997.

LIBARDI, P.L. \& van LIER, Q.J . Atuação dos fatores físicos do solo no desenvolvimento do sistema radicular. In: WORKSHOP SOBRE DESENVOLVIMENTO DO SISTEMA RADICULAR: METODOLOGIAS E ESTUDO DE CASOS, 1., Aracaju, 1999. Anais. Aracaju, Embrapa Tabuleiros Costeiros, 1999. p.268-273.
MACÊDO, J .L.V. \& RODRIGUES, M.R.L. Solos da amazônia e o cultivo do dendezeiro. In: VIÉGAS, I.J.M. \& MÜLLER, A.A., eds. A cultura do dendezeiro na amazônia brasileira. Belém, Embrapa - Amazônia Oriental/Manaus, Amazônia Ocidental, 2000. p.115-128.

MEDINA, C.C. \& NEVES, C.S.V.J . Método da trincheira com contagem manual das raízes. In: WORKSHOP SOBRE DESENVOLVIMENTO DO SISTEMA RADICULAR: METODOLOGIAS E ESTUDO DE CASOS, 1., Aracaju, 1999. Anais. Aracaju, Embrapa Tabuleiros Costeiros, 1999. p.275-282.

OLIVEIRA, F.C. Metais pesados e formas nitrogenadas em sol os tratados com lodo de esgoto. Piracicaba, Escola Superior de Agricultura "Luiz deQueiroz", 1995. 90p. (Tese de Mestrado)

PASSOS, E.M.P. Morfologia do coqueiro. In: FERREIRA, J .M.S. WARWICK D.R.N. \& SIQUEIRA, L.A., eds. A cultura do coqueiro no Brasil. Brasília, Embrapa, 1997. p.57-64.

RAIJ , B. van \& QUAGGIO,J .A. Determinação de fósforo, cálcio, magnésio e potássio extraídos com resina trocadora deíons. In: RAIJ , B. van; ANDRADE, J .C.; CANTARELLA, H. \& QUAGGIO, J.A., eds. Análise química para avaliação da fertilidade de solos tropicais. Campinas, Instituto Agronômico, 2001. 285p.

RAMOS, A. Análise do desenvolvimento vegetativo e produtividade da palmeira pupunha (Bactris gasipaes Kunth) sob níveis de irrigação e adubação nitrogenada. Piracicaba, Escola Superior de Agricultura "Luiz de Queiroz", 2002. 113p. (Tese de Doutorado)

SCHROTH, G.; D'ANGELO, S.A.; SCHALLER, M.; HAAG, D. $\&$ RODRIGUES, M.R.L. Root research methods for humid tropical agro-forestry systems - a management perspective. In: WORKSHOP SOBRE DESENVOLVIMENTO DO SISTEMA RADICULAR: METODOLOGIAS E ESTUDO DE CASOS, 1., Aracaju, 1999. Anais. Aracaju, Embrapa Tabuleiros Costeiros, 1999. p.219-230.

SILVA, L.M.V. \& PASQUAL, A. Dinâmica e modelagem da matéria orgânica do sol o com ênfase ao ecossistema tropical. Ener. Agric., 14:13-24, 1999

TOMLINSON, P.B. The structural biology of palms. Oxford, Clarendon Press, 1990. 463p.

TSUTIYA, M.T. Alternativas de disposição final de biossólidos. In: TSUTIYA, M.T.; CAMPARINI, J.B.; ALEM SOBRINHO, P.; HESPANHOL, I.; DE CARVALHO,P.C.T.; MELFI, A.J .; MELO, W.J . \& MARQUES, M.O., eds. Biossólidos na agricultura. São Paulo, SABESP, 2001. p.133-178.

VANDERMEER, J. Observations on the root system of the pejibaye palm (Bactris gasipaes H.B.K.) in Costa Rica. Turrialba, 27:237-242, 1977

VEGA, F.V.A. Uso de lodo de esgoto na implantação da cultura da pupunheira (Bactris gasi paes Kunth). Campinas, I nstituto Agronômico de Campinas, 2003. 129p. (Tese de Mestrado)

VILLACHICA, H.L. Cultivo de pijuayo (Bactris gasi paes Kunth) para palmito en la amazonia. Tratado de Cooperación Amazónica, Lima - Perú, 1996. 146p.

YANEZ, P.B.; RIOS, G.J .; SANDOVAL, B.F. \& COSSIO, F.G. Materia orgánica y caracterización con coberturas vegetativas en zonas templadas do México. Terra, 17:139$148,1999$. 